\title{
The approach and proximity behavior of spiny mouse pups (Acomys cahirinus) toward strange neonates: Effects of gender and species of stimulus pup
}

\author{
RICHARD DENI, SUSAN WILSON, and DONNA REISERT \\ Rider College, Lawrenceville, New Jersey 08648
}

\begin{abstract}
Three experiments were done using male and female spiny mice (Acomys cahirinus) as subjects observed in the presence of both a male and a female newborn stimulus pup. Stimulus pups were either strange spiny mice or Norway rats (Rattus norvegicus). The object of the experiments was to record physical approach and proximity behavior. Individual spiny mouse pups were observed in a small cage with two unfamiliar neonates (one of each sex) as stationary stimuli. Betweensubjects variables included the gender and age (1-2 days; 10-11 days) of the spiny pup. The dependent measure used throughout was the duration of time, within a 5-min exposure session, that each subject occupied two proximity zones established around each stimulus pup. In Experiment 1, spiny pups were tested with live newborn rat pups as choice stimuli, and the results indicated that 1- to 2-day-old female spiny pups spent significantly more time positioned near the opposite-sex pup than near the same-sex stimulus rat pup. Experiment 2 was a replication using dead newborn rat pups as choice stimuli to remove any behavioral cues that might have contributed to sex differentiation by female spiny mice. The choice behavior of 1- to 2-dayold female spiny mice was similar to that obtained in Experiment 1. Experiment 3 was a replication with live newborn spiny mice as stimuli; however, no choice preferences were found, suggesting that the sex-differentiation capability observed in Experiment 1 may have been exclusively interspecific. These findings were discussed in terms of sex differences among spiny mouse pups for measures of neophobia and exploratory and predatory behavior and in terms of an odor-based sex-discrimination capability.
\end{abstract}

The Norway rat (Rattus norvegicus) has been studied under natural, seminatural, and laboratory-experimental circumstances to establish the conditions under which optimal social behaviors are expressed. This species is well suited for studies of offspring-parent interactions because the young are altricial and progress through an orderly slow series of developmental steps for physiomuscular, sensory, and behavioral competencies. Norway rats are less well suited for studies of very early pup-pup interactions for the same reason. Nevertheless, significant progress has been made toward an understanding of very early social behavior by rat pups using experimental methods.

For example, Alberts (1978) reported that 5-day-old rat pups approached and huddled with inanimate target stimuli based on thermal cues. A warm loop of tubing was an effective stimulus for eliciting approach and huddling behavior. Pups greater than 10 days of age were attracted to target stimuli based apparently on their resemblance to conspecifics. Dead ambient-temperature

Address reprint requests to Richard Deni, Psychology Department, Rider College, Lawrenceville, New Jersey 08648. We thank Lisa Budzek, Debra Hercek, Joanne Lietz, Rene Piper, and Susan Snow for their assistance. pups were huddled against. However, blockage of olfactory input by administration of intranasal zinc sulfate disrupted huddling with live conspecifics. Alberts and Brunjes (1978) described the age-related transition from thermal to olfactory cue reliance as an indication that actual "filial" huddling was directed by responses to species odors. Experimental studies of this type, using individual rat pups, have been successful in setting the framework for early rodent social behavior as odor guided and that for very early social behavior as temperature guided.

Physical approach and proximity studies of the newborn are more practical if a precocial species is used. The use in recent years of spiny mice (Acomys cahirinus) in studies of parent-offspring and sibling interaction has begun to augment the limited usefulness of Norway rat pups in the age range of 1-2 days old. The highly precocial spiny mouse newborn has hair and apparently functional auditory and visual capability at birth. Locomotor activity at birth is also precocial, thus allowing for behavioral tests involving movement, selection of sites, and choice alternatives in a test environment (cf. Porter \& Doane, 1978).

The objectives of the experiments in the series reported here were twofold. First, will the gender or age 
of young spiny mice affect differential choice behavior directed toward newborns of an alien species (Norway rats) and conspecific newborns? Second, if approach and proximity responses vary as a function of subject or stimulus factors, are the responses under the control of behavioral or odor cues in the stimulus animals?

\section{GENERAL METHOD}

\section{Subjects}

Spiny mouse pups, used either as subjects or as approachchoice stimuli, and Norway rat pups, used as approach-choice stimuli, were obtained by random selection from available litters born in the colonies maintained at Rider College. Litters were housed in standard plastic cages, with pine shavings as bedding material and rat chow and water always available. Rat litters were housed with the dam present, but spiny mouse litters were housed with both parents. When pups of a specific age were obtained from a given litter for testing on a given day, that litter had no further involvement in the studies.

\section{Apparatus}

The cage used for all observations consisted of a translucent polypropylene rodent cage bottom $45 \mathrm{~cm}$ long $\mathrm{x} 25 \mathrm{~cm}$ wide $\mathrm{x}$ $22 \mathrm{~cm}$ high. During observations, two small metal strainer baskets, $7 \mathrm{~cm}$ in diameter, were used to cover and keep stationary each of two stimulus pups placed in the cage. The uncovered cage was located on the floor of a small room separate from the colony room. A video camera mounted on a tripod was positioned over the open cage to record the movement of the subject during testing. All observations were recorded on video cassette for later playback and coding. Both flourescent and incandescent overhead lighting were present inside the observation room. The air temperature was maintained at $70^{\circ} \mathrm{F}-73^{\circ} \mathrm{F}$.

\section{Procedure}

Two stimulus pups. one of each sex, were obtained prior to each observation session, and each was placed under a metal strainer basket located at either end of the observation cage. The right-left positioning of the baskets and the orientation of the cage under the video camera were determined at random. Prior to each session, the cage was cleaned and filled with fresh pine shavings to a depth of $3 \mathrm{~cm}$. After the stimulus pups were in position under each strainer cover, a subject pup was obtained and placed in the center of the observation cage. The transfer of subject pups was done using a clean glass beaker as a "scoop" to avoid hand contact. Two small index cards were placed near the cage within the view of the camera to serve as session, subject, and condition labels. The gender of each stimulus pup was labeled in this way. Each session began with a 2-min adaptation period followed by a 5-min period during which the location of the subject pup was recorded.

The dependent variable consisted of the duration (in seconds) of time the subject pup spent in proximity to each stimulus pup. The rectangular test cage was divided into proximity zones during the coding of videotapes. Two duration scores were obtained from each coding session: total time within $15 \mathrm{~cm}$ of each of the two stimulus pups. The two proximity zones were traced along a circular arc with the center point of the strainer cover as center of the circle. The two zones did not overlap. The total duration of time spent by a subject within each zone was recorded to the nearest $.1 \mathrm{sec}$. Periodic assessments of interobserver reliability were carried out during all experiments, with all agreement scores above $95 \%$.

\section{Data Analysis}

Differences in proximity as a function of groups and conditions were tested using three-factor mixed-factorial analyses of variance (Kirk, 1968, p. 283). In each case, the between-subjects factors were gender and age and the within-subjects factor was the type of the stimulus animal (same sex as subject or opposite). Post hoc tests, when appropriate, were performed using NewmanKeuls multiple comparisons.

\section{EXPERIMENT 1}

In this study, groups of spiny mice were observed in a locomotor approach-choice situation with two live newborn rat pups, one of each sex, as stimuli.

\section{Method}

A total of 36 spiny mice were used as subjects. Two age groups were used, consisting of 18 mice tested at 1-2 days of age and 18 mice tested at 10-11 days of age. Within each age group were two gender groups, each with nine male and nine female mice. Each subject was tested on a single day, and the test session was videotaped. The basic objective of the observation was to measure the time the subject spent in proximity to either the male or the female stimulus rat pup during a brief exposure period.

\section{Results and Discussion}

Two scores were obtained for each subject, including the duration (in seconds) of time spent within the proximity zones of the same- and opposite-sex stimulus rat pups.

There was a significant three-way interaction among all factors in the design $[\mathrm{F}(1,32)=4.32, \mathrm{p}<.05]$ (see Table 1). Specific-comparison tests showed that for female 1- to 2-day-old spiny mice, significantly more time was spent near the opposite- than near the same-sex rat pup $(\mathrm{p}<.05)$. Very young female infant spiny mice differed markedly from all other groups in their apparent ability to differentiate between same- and opposite-sex newborn rat pups during a brief exposure period. These findings do not match previous reports of the social behavior of infant spiny mice directed toward parents and siblings. Porter, Cavallaro, and Moore (1980), for example, reported that infant spiny mice gradually increase their social huddling with parents and siblings over the period of 1-10 days of age. However, Table 1 shows no similar age trend for approach toward new-

Table 1

Means and Standard Deviations of Time Spent Near Both

Same- and Opposite-Sex Newborn Rat Pups by Infant Spiny Mice Tested in an Approach-Choice Situation During a Single 5-Min Period

\begin{tabular}{lll}
\hline Condition & Mean & SD \\
\hline
\end{tabular}

Three-Way Interaction:

Age by Sex of Subject by Type of Stimulus

1- to 2-Day-Old Males

Same-Sex Rat Pup

Opposite-Sex Rat Pup

126.4

133.4

131.8

1- to 2-Day-Old Females

Same-Sex Rat Pup

Opposite-Sex Rat Pup

10- to 11-Day-Old Males

Same-Sex Rat Pup

115.1

112.7

Opposite-Sex Rat Pup

101.1

10- to 11-Day-Old Females

Same-Sex Rat Pup

117.3

76.2

Opposite-Sex Rat Pup 
born rat pups of either sex. Previous reports of the social behavior of infant spiny mice can offer only a speculative explanation for the finding here that very young females were the only group to show differential behavior toward newborn rat pups. In particular, Porter et al. (1980) described a small and statistically nonsignificant sex difference for young spiny mice with regard to the age for initial feeding on solid food. According to the authors, females were seen eating solid food 1 day, on average, earlier than males. Perhaps the differential approach behavior of 1- to 2-day-old female spiny mice was the result of their reduced neophobia compared to very young males and older pups of both sexes.

\section{EXPERIMENT 2}

In this study, groups of spiny mice were observed in a physical approach-choice situation with two dead newborn rat pups, one of each sex, as stimuli. Dead stimulus pups were presented to attempt to isolate the mechanism used by spiny mice to differentiate same- from opposite-sex rat pups. Stimulus pups sacrificed immediately before testing would emit the species odor in the absence of any behavioral cues, and odor has been regarded by other researchers as the basis for the control of filial huddling in rat pups prior to weaning (Alberts \& Brunjes, 1978) and the proposed mechanism by which rat dams discriminate among their offspring (Moore, 1981; Moore \& Morelli, 1979). The objective of this study was to determine whether, in the absence of behavioral cues, spiny mice would still show differential approach behavior toward same- vs. opposite-sex rat pups.

\section{Method}

A total of 40 spiny mice were used as subjects. Two age groups and two gender groups were used, as in Experiment 1, resulting in 10 subjects assigned to each combination of the two between-subjects variables. The details of procedure and testing were the same as in Experiment 1, with the exception that dead newborn rat pups were used as stimuli. Thirty minutes prior to each observation, two rat pups, one of each sex, were selected at random and sacrificed by carbon dioxide asphyxiation. Pups to be sacrificed were placed inside a small plastic container through which the gas was circulated for $30 \mathrm{~min}$. Dead stimulus pups were handled similarly to live pups used in Experiment 1.

\section{Results and Discussion}

Two scores were obtained for each subject, representing the duration of time spent within the proximity zones of the same- and opposite-sex stimulus rat pups. The statistical analysis showed a significant three-way interaction among all factors in the design $[F(1,36)=$ $6.40, \mathrm{p}<.05]$. Table 2 shows the means and standard deviations for the combinations in this interaction. Specific-comparison tests showed that for male and female 1- to 2-day-old spiny mice, duration of proximity to same- vs. opposite-sex dead rat pups was significantly different $(\mathrm{p}<.05)$. However, very young male spiny
Table 2

Means and Standard Deviations of Time Spent Near Both Same- and Opposite-Sex Dead Newborn Rat Pups by Infant Spiny Mice Tested in an Approach-Choice Situation During a Single 5-Min Period

Three-Way Interaction: Age by Sex of Subject by Type of Stimulus

\begin{tabular}{|c|c|c|}
\hline Condition & Mean & SD \\
\hline \multicolumn{3}{|c|}{ 1- to 2-Day-Old Males } \\
\hline $\begin{array}{l}\text { Same-Sex Dead Rat Pup } \\
\text { Opposite-Sex Dead Rat Pup }\end{array}$ & $\begin{array}{r}192.1 \\
48.7\end{array}$ & $\begin{array}{l}132.4 \\
104.8\end{array}$ \\
\hline \multicolumn{3}{|c|}{ 1- to 2-Day-Old Females } \\
\hline $\begin{array}{l}\text { Same-Sex Dead Rat Pup } \\
\text { Opposite-Sex Dead Rat Pup }\end{array}$ & $\begin{array}{r}76.2 \\
146.1\end{array}$ & $\begin{array}{l}117.6 \\
141.3\end{array}$ \\
\hline \multicolumn{3}{|c|}{ 10- to 11-Day-Old Males } \\
\hline $\begin{array}{l}\text { Same-Sex Dead Rat Pup } \\
\text { Opposite-Sex Dead Rat Pup }\end{array}$ & $\begin{array}{l}101.7 \\
128.4\end{array}$ & $\begin{array}{l}41.5 \\
38.4\end{array}$ \\
\hline \multicolumn{3}{|c|}{10 - to 11-Day-Old Females } \\
\hline $\begin{array}{l}\text { Same-Sex Dead Rat Pup } \\
\text { Opposite-Sex Dead Rat Pup }\end{array}$ & $\begin{array}{r}112.0 \\
89.2\end{array}$ & $\begin{array}{l}51.7 \\
34.8\end{array}$ \\
\hline
\end{tabular}

mice spent more time near dead same-sex rat pups, whereas very young female spiny mice spent more time near dead opposite-sex rat pups. These findings support the results of Experiment 1 and the explanation of the females' behavior as a result of less neophobia compared with that of males. For example, if very young male spiny mice are more neophobic than females, they might investigate a dead stimulus pup more readily than a live one. This, of course, does not explain why males apparently preferred to be near same- rather than opposite-sex dead rat pups. However, the pattern of proximity behavior for very young female spiny mice reported in Experiment 1 was replicated here with dead newborn rat pups as stimuli. Female spiny mice apparently preferred opposite- over same-sex rat pups whether they were alive or dead, suggesting that olfactory stimuli play a role in the differentiation process. For 1- to 2-day-old female spiny mice, at least, possible identifying behavioral cues in stimulus rat pups seem to be irrelevant in determining the pattern of physical choice and proximity between stimulus pups of either sex.

\section{EXPERIMENT 3}

In this final study, groups of spiny mice were observed in the approach-choice situation with two live newborn spiny mouse pups, one of each sex, as stimuli. These test conditions were designed to determine if the Sex by Stimulus interaction effect obtained in Experiment 1 would also occur when stimulus pups were conspecifics.

\section{Method}

A total of 36 spiny mice were used as subjects. As in the first two experiments, two age groups and two gender groups were used, resulting in nine subjects assigned to each combination of the two between-subjects variables. All procedural details were the same as those used in Experiment 1, with the exception that 1- to 2-day-old spiny mice were used as stimulus pups. 


\section{Results and Discussion}

As in the two previous experiments, two scores were obtained for each subject, representing the duration of time in proximity to the same- and opposite-sex stimulus spiny pups. The statistical analysis resulted in no significant main effects or interactions.

The findings of Experiment 3 can provide reinforcement for the results reported in the first two experiments. In particular, the explanation based on sex differences in fear level for very young spiny mice can also be applied here. Since the stimulus choices were conspecifics, they represented the most familiar stimulus type and, apparently, elicited undifferentiated approach responses.

\section{GENERAL DISCUSSION}

There are two major findings from these experiments. First, very young female spiny mice consistently differentiate between same- and opposite-sex newborn rat pups, keeping physically closer to opposite-sex pups whether those stimulus animals are alive or dead. Second, no such pattern of differential approachchoice behavior was found for male spiny mice tested with live rat pups as stimuli. However, with dead rat pups as stimuli, very young male spiny mice did differentiate and apparently preferred to keep near same-sex dead rat pups. While this particular array of findings is certainly unexpected, there are avenues by which to approach the problem of explanation.

Limited evidence has been reported concerning the possible ability of young rat pups to differentiate sibling huddlemates according to sex (Deni, Miele, Wilson, Longo, Miernicki, \& Silvers, 1982). Specifically, the authors reported that for both sexes overall, there was a tendency to huddle more with oppositethan with same-sex siblings. From the present data, spiny mice do not share this sex-discrimination capability when strange conspecific stimulus pups are used in a choice-proximity test (Experiment 3), but they do show a marked sex differentiation when stimulus pups from another species are used (Experiment 1) and when the stimulus animals are dead (Experiment 2). The limiting factor, however, in determining the roots of these effects is the very nature of the interactions. These differential patterns in physical proximity were consistent only for the youngest female spiny mice tested (1-2 days old). In the single case when a similar pattern was found among male spiny mice, the preference was in the opposite direction (same over opposite sex).

The results of Experiment 2, in part, rule out an explanation based on differential behavior by the stimulus pups of each sex, but they leave open the suggestion that young female spiny mice made their discriminations based on odor. The ability of rodent pups to discriminate species odor has been consistently reported in the context of sibling huddling in rats (Alberts, 1978; Brunjes \& Alberts, 1979) and parent-offspring attraction in rats (Leon, 1975 ) and spiny mice (Porter, Deni, \& Doane, 1977; Porter \& Doane, 1976). Explanations for the interaction effects reported in Experiments 1 and 2 here can be only tenuous, however, when based entirely on odor. For example, it may be that very young spiny mice, because of their relative lack of experience, detected certain salient features of sex-specific odor in rat neonates not detected by older spiny mice. Moore (1981), for example, has reported that rat pups produce a sex-specific olfactory cue that stimulates differential maternal licking. The essential result of the present series of studies is to introduce the position that such odor-based sex-differentiation mechanisms are more general than first predicted.

The present data clearly suggest new directions for research on early intra- and interspecific social behavior in rodents. For example, one possible interpretation of the data reported here may include reference to predatory behavior or attack behavior by very young spiny mice. Physical attraction, or, at least, proximity, is a prerequisite for such behavior. The properties of newborn rat pups likely to elicit biting and feeding by hungry adults (e.g., a smooth thin coat) have been documented for intraspecific feeding encounters between adult Norway rats and pups (Carr, Dissinger, \& Scannapieco, 1982). A similar analysis for subadult spiny mice will place the present data on physical proximity tendencies in perspective.

\section{REFERENCES}

Alberts, J. Huddling by rat pups: Multisensory control of contact behavior. Journal of Comparative and Physiological Psychology, 1978, 92, 220-230.

Alberts, J., \& Brunjes, P. Ontogeny of thermal and olfactory determinants of huddling in the rat. Journal of Comparative and Physiological Psychology, 1978, 92, 897-906.

Brunjes, P., \& Alberts, J. Olfactory stimulation induces filial preferences for huddling in the rat. Journal of Comparative and Physiological Psychology, 1979, 93, 548-555.

Carr, W. H., Dissinger, M. L., \& Scannapieco, M. R. The stimulus-basis of a natural food aversion in Norway rats. Physiology \& Behavior, 1982, 28, 281-287.

Deni, R., Miele, J., Wilson, S., Longo, J., Miennicki, M., \& Silvers, M. Effect of cross-litter pup and cage bedding exchanges on huddling in rat pups. Psychological Record, 1982, 32, 543-549.

KinK, R. E. Experimental design: Procedures for the behavioral sciences. Belmont, Calif: Brooks/Cole, 1968.

LEON, M. Dietary control of maternal pheromone in the lactating rat. Physiology \& Behavior, 1975, 14, 311-319.

Moore, C. L. An olfactory basis for maternal discrimination of sex of of fspring in rats. (Rattus norvegicus). Animal Behaviour, 1981, 29, 383-386.

Moore, C. L., \& Morelli, G. A. Mother rats interact differently with male and female offspring. Journal of Comparative and Physiological Psychology, 1979, 93, 677-684.

Porter, R. H., Cavallaro, S. A., \& Moore, J. D. Developmental parameters of mother-offspring interactions in Acomys cahirinus. Zeitschrift für Tierpsychologie, 1980, 53, 153-170.

Porter, R. H., Deni, R., \& Doane, H. M. Responses of Acomys cahirinus pups to chemical cues produced by a foster species. Behavioral Biology, 1977, 20, 244-251.

Porter, R. H., \& Donne, H. M. Maternal pheromone in the spiny mouse (Acomys cahirinus). Physiology \& Behavior, 1976, 16, 75-78.

Porter, R. H., \& Donne, H. M. Studies of maternal behavior in spiny mice (Acomys cahirinus). Zeitschrift für Tierpsychologie, 1978, 47, 225-235.

(Received for publication February 11, 1983.) 